\title{
Budidaya Lebah Klanceng sebagai Ekonomi Alternatif Masyarakat Sekitar KHDTK Gunung Bromo UNS
}

\author{
Dwi Priyo Ariyanto $^{1}$, Ana Agustina ${ }^{2 *}$, Widiyanto ${ }^{3}$ \\ ${ }^{1}$ Program Studi Ilmu Tanah, Fakultas Pertanian, Universitas Sebelas Maret \\ ${ }^{2}$ Program Studi Pengelolaan Hutan, Fakultas Pertanian, Universitas Sebelas Maret \\ ${ }^{3}$ Program Studi Penyuluhan dan Komunikasi Pertanian, Fakultas Pertanian, \\ Universitas Sebelas Maret \\ *Corresponding Author: ana.agustina2018@staff.uns.ac.id
}

\begin{abstract}
ABSTRAK
Universitas Sebelas Maret (UNS) Surakarta mempunyai hak pengelolaan atas Kawasan Hutan Dengan Tujuan Khusus (KHDTK) Gunung Bromo UNS yang terletak di Kabupaten Karanganyar. Salah satu permasalahan dalam pengelolaan adalah masyarakat sekitar KHDTK Gunung Bromo UNS yang mata pencahariannya masih bergantung pada Hutan Gunung Bromo. Sebagian masyarakat di sekitar KHDTK Gunung Bromo UNS memanfaatkan beberapa lahan untuk kegiatan pertanian yang sangat dimungkinkan kerusakan lingkungan hutan akan terjadi. Untuk meningkatkan pendapatan masyarakat dapat melalui usaha budidaya lebah madu klanceng. Kegiatan pemberdayaan masyarakat ini dilaksanakan di KHDTK Gunung Bromo UNS dengan melibatkan Karang Taruna Kelurahan Gedong dan Karang Taruna Kelurahan Delingan, Kecamatan Karanganyar, Kabupaten Karanganyar. Tujuan kegiatan ini adalah untuk meningkatkan produktivitas masyarakat yang diikuti dengan peningkatan pendapatan dan kesejahteraan melalui produksi lebah madu klanceng. Bentuk kegiatan yang dilakukan berupa pelatihan kelas dan praktik budidaya lebah klanceng. Kegiatan pengabdian yang telah dilaksanakan mendapatkan respon positif dari pihak masyarakat, hal ini ditunjukkan melalui antusias para peserta pelatihan budidaya lebah Klanceng. Bersama Pengelola KHDTK Gunung Bromo UNS, tim pengabdian telah membentuk Kelompok Tani Pengelola Lebah Klanceng. Meskipun saat ini belum ada peningkatan pendapatan yang dirasakan oleh masyarakat, akan tetapi kesesuaian lokasi dan teknik budidaya yang relatif mudah untuk dilakukan menjadi faktor pendukung dalam berkembangnya budidaya lebah klanceng di KHDTK Gunung Bromo UNS.
\end{abstract}

Kata Kunci: KHDTK Gunung Bromo, lebah madu klanceng, pemberdayaan masyarakat

\section{ABSTRACT}

Universitas Sebelas Maret (UNS) Surakarta have management rights over forest with special purposes KHDTK Gunung Bromo UNS located in Karanganyar District. The problems in management is the community people around KHDTK Gunung Bromo UNS that still depends on his livelihood. Some communities around KHDTK Gunung Bromo UNS used lands to the agricultural sector thus the probability of damage occurs environment it can happen. To increase the community income can be done by cultivating Trigona bee. This community empowerment activity will be carried out at KHDTK Gunung Bromo UNS by involving Youth Organization of Gedong Village and Youth Organization of Delingan Village, Karanganyar District, Karanganyar Regency. Aim of this activity to increase income of community trough Trigona bee cultivation. Activities include theoretical training and cultivation practice. Positive responses were given for this activity through community enthusiastic. With KHDTK Gunung Bromo UNS Management, the team forming a new group as Trigona Bee community. Although until this time the cultivation has not affected to community income but location suitability and convenience cultivation technique factor support develop of Trigona bee cultivation in KHDTK Gunung Bromo UNS.

Keywords: KHDTK Gunung Bromo, trigona bee, community development 


\section{PENDAHULUAN}

Hutan merupakan kawasan yang sangat penting bagi siklus ekosistem dan lingkungan. Keberadaan hutan saat ini semakin menurun atau mengalami deforestasi. Di Indonesia, angka deforestasi pada tahun 2017 tercatat sebesar 480 ribu hektar. Angka tersebut memang menurun dibandingkan tahun 2016 yang mencapai 630 ribu hektar dan tahun 2015 mencapai 1,09 juta hektar (KLHK, 2018b). Namun demikian, deforestasi yang terus terjadi dapat menyebabkan kerusakan hutan dan fungsinya sehingga berdampak pada kerusakan lingkungan serta dapat menyebabkan bencana alam.

Beberapa kegiatan yang diduga sebagai penyebab deforestasi diantaranya intensifnya pengelolaan hutan pada areal Izin Usaha Pemanfaatan Hasil Hutan Kayu (IUPHHK); konversi kawasan hutan untuk penggunaan sektor lain; perambahan dan okupasi lahan pada kawasan hutan; pencurian kayu atau penebangan liar; serta kebakaran hutan (KLHK, 2018a). Penyebab utama deforestasi adalah untuk kepentingan pertanian (Sunderlin \& Resosudarmo, 1997). Deforestasi juga diduga menyebabkan efek global berupa adanya perubahan iklim yang ditandai dengan pemanasan atau peningkatan suhu secara global dan atau pergeseran pola musim. Efek ini berdampak pada kerusakan lingkungan yang ditandai dengan peningkatan bencana hidrometeorologi atau bencana alam yang disebabkan oleh cuaca secara umum.

Untuk mengurangi kerusakan hutan, khususnya yang disebabkan oleh kepentingan pertanian, beberapa pendekatan telah dilakukan, baik oleh dinas kehutanan maupun pengelola kawasan hutan, seperti Perum Perhutani yang merupakan perusahaan umum milik negara sebagai pengelola kawasan hutan di Pulau Jawa. Pihak Perum Perhutani telah merangkul masyarakat sekitar hutannya dengan pembentukan Lembaga Masyarakat Desa Hutan (LMDH). LMDH dibentuk berdasarkan desa di sekitar hutan yang merupakan mitra dari Perum Perhutani. Kegiatan yang diwadahi dalam organisasi ini lebih pada kegiatan budidaya pertanian di kawasan hutan yang sedang mengalami peremajaan pohon, sehingga masyarakat dapat mengelola lahan menjadi mata pencaharian tambahan. Akan tetapi, terkadang timbul konflik kepentingan misalnya pada beberapa kasus masyarakat merusak tanaman pokok hutan yang dinilai menghambat usaha pertaniannya. Hal ini tentu saja berdampak pada kelestarian hutan. Selain itu, kepedulian masyarakat terhadap kelestarian hutan harus ditingkatkan dengan memberikan pengetahuan dan wawasan lingkungan.

Salah satu cara yang dapat dilakukan untuk meningkatkan kepedulian masyarakat adalah dengan pemanfaatan Hasil Hutan Bukan Kayu (HHBK) yang bisa diperoleh dari kawasan hutan. Adapun jenis HHBK yang dapat dikembangkan salah satunya adalah lebah madu klanceng. Budidaya lebah madu klanceng memiliki potensi untuk dikembangkan karena kemudahan dalam pengelolaan budidaya serta permintaan pasar dan harga jual terhadap produk madu dan propolis yang tinggi (Syaifudin, 2020). Kondisi lingkungan meliputi suhu, kelembaban, dan ketinggian suatu wilayah akan mempengaruhi produktivitas lebah klanceng (Kerisna et al., 2019). Di beberapa wilayah di Indonesia sudah banyak dilakukan budidaya lebah klanceng dan menjadi sumber ekonomi alternatif bagi masyarakat (Ahmad, 2020; Elpawati et al., 2019; Pribadi, 2020). Kegiatan pengabdian kepada masyarakat ini dilakukan dengan pemberdayaan melalui budidaya lebah madu klanceng yang diperuntukkan pada masyarakat yang tergabung dalam karang taruna di sekitar Kawasan Hutan Dengan Tujuan Khusus (KHDTK) Gunung Bromo UNS di Karanganyar. Tujuan kegiatan ini dilaksanakan untuk meningkatkan produktivitas masyarakat yang diikuti dengan peningkatan pendapatan dan kesejahteraan melalui produksi lebah madu klanceng.

\section{METODE}

Kegiatan dilaksanakan di KHDTK Gunung Bromo UNS yang secara administrasi berada di Kelurahan Gedong dan Kelurahan Delingan, Kecamatan Karanganyar, Kabupaten Karanganyar. Masyarakat yang menjadi sasaran pada kegiatan pengabdian ini adalah kelompok Karang Taruna Tunas Harapan Kelurahan Gedong dan Karang Taruna Bakti Manunggal Kelurahan Delingan, Kecamatan Karanganyar, Kabupaten Karanganyar. Karang taruna tersebut secara resmi berada dalam pembinaan masingmasing kelurahan dan mempunyai sub unit karang taruna di tingkat dusun atau kampung. Kegiatan dilaksanakan secara simultan sejak bulan Maret sampai dengan Oktober 2020. Adapun tahapan pelaksanaan kegiatan adalah sebagai berikut: 


\section{Survei Pra Kegiatan}

Tahapan ini merupakan persiapan yang dilakukan dengan melihat kondisi lingkungan agar bisa disesuaikan dengan kegiatan budidaya lebah madu klanceng. Selain melihat kondisi lingkungan, sekaligus akan dilakukan pendekatan kepada mitra karang taruna untuk mempersiapkan anggotanya yang bersedia mengikuti kegiatan dari awal sampai akhir sesuai jadwal yang disepakati bersama.

\section{Pelatihan kelas}

Tahapan pelatihan kelas adalah pemberian pelatihan secara teori kepada peserta dengan memberikan penjelasan dan gambaran mengenai budidaya lebah madu klanceng. Kegiatan ini lebih banyak menggunakan peralatan kelas seperti presentasi menggunakan projector dilanjutkan dengan diskusi dari penjelasan teori berikut contoh-contoh kasusnya. Dalam kegiatan ini juga dilihat antusias dari para peserta mengenai budidaya lebah madu klanceng.

\section{Pelatihan praktik}

Tahapan pelatihan praktik adalah pemberian pelatihan kepada peserta langsung di lapangan berikut contoh budidaya lebah madu, mulai dari persiapan lahan, budidaya tanaman bunga sebagai makanan lebah, perawatan lebah sampai dengan pemanenan madu dari sangkar atau rumah lebah. Beberapa hal yang perlu diperhatikan dalam budidaya lebah madu klanceng yaitu: menentukan lokasi budidaya, membuat sarang lebah klanceng, membuat koloni dari sarang buatan, perawatan, dan pemeliharaan.

\section{Pemanenan}

Pemanenan dilakukan pada saat bulir-bulir madu dalam sarang terlihat. Pembentukan bulirbulir madu berlangsung selama 3-4 bulan. Tetapi juga tergantung dengan jumlah koloni dan lebah yang dimiliki dalam budidaya. Semakin banyak koloni dan sarang maka madu yang akan dipanen semakin banyak. Oleh karena itu, pembentukan koloni baru harus dilakukan secara kontinu supaya panen madu bisa dipanen yang kontinu. Diperlukan teknik yang tepat dan memadai saat proses pemanenan sehingga diperoleh hasil yang maksimal.

\section{Pendampingan Pengelolaan dan Produk}

Setelah diberikan pelatihan, kelompok peserta akan diberikan starter set lebah yang akan dikelola secara kelompok di KHDTK
Gunung Bromo UNS. Peserta juga dapat melakukan praktek individu atau secara sendiri di rumah maupun lokasi yang diinginkan. Selama perawatan, akan dilakukan pendampingan atau klinik bimbingan bagi peserta jika menemui kesulitan atau hambatan. Klinik bimbingan dapat dilakukan melalui aplikasi pesan daring atau dengan kesepakatan pertemuan di KHDTK Gunung Bromo UNS.

Selain itu, juga akan dilakukan pendampingan dalam pendaftaran produk ke BPOM agar produk yang dihasilkan bisa dijual di pasaran sesuai aturan yang berlaku.

\section{Monitoring dan Evaluasi}

Melalui kegiatan monitoring dan evaluasi dapat diketahui keberhasilan pelaksanaan kegiatan pengabdian lebah klanceng di KHDTK Gunung Bromo meliputi: jumlah peserta yang hadir, perwakilan masing-masing kelurahan, dan keterlibatan lebih lanjut sebagai anggota Kelompok Tani Lebah.

\section{HASIL DAN PEMBAHASAN}

Kegiatan pengabdian ini dilakukan guna menciptakan sumber mata pencaharian alternatif bagi masyarakat sekitar KHDTK Gunung Bromo UNS. Adapun kegiatan-kegiatan yang telah dilakukan bersama masyarakat adalah sebagai berikut:

\section{Survey Pra Kegiatan}

Kegiatan survey sebelum kegiatan dimulai dilakukan untuk melihat kesesuaian rencana pengelolaan lebah klanceng di KHDTK Gunung Bromo, selanjutnya juga memperhatikan respon dari masyarakat sekitar KHDTK Gunung Bromo. Setelah dilakukan pertemuan dengan perwakilan Karang Taruna Kelurahan Delingan dan Gedong, dan mendapatkan respon positif maka kegiatan pengabdian ini dapat dilaksanakan. Masyarakat berharap budidaya lebah klanceng dapat menjadi salah satu sumber ekonomi alternatif ke depannya. Di samping itu, keterlibatan masyarakat dalam mengelola lebah klanceng di KHDTK Gunung Bromo akan memberikan dampak positif dalam pengelolaan hutan ke depannya. Masyarakat secara tidak langsung akan turut serta dalam melestarikan kawasan hutan.

\section{Pelatihan Kelas}

Kegiatan dilaksanakan di KHDTK Gunung Bromo bersama dengan Karang Taruna 
Tunas Harapan dan Karang Taruna Bakti Manunggal. Penyampaian materi disampaikan oleh narasumber dari peneliti dan praktisi lebah. Kegiatan pelatihan kelas dilakukan di pendopo KHDTK Gunung Bromo UNS dengan menjalankan standar protokol pandemi Covid19 (Gambar 1). Kegiatan ini juga didukung penuh oleh pihak kelurahan, karena merupakan salah satu kegiatan positif yang tentu saja akan memberikan manfaat kepada masyarakat. Adapun materi yang disampaikan berkenaan dengan pengenalan jenis lebah, pakan lebah, produk yang dihasilkan, dan teknik budidaya.

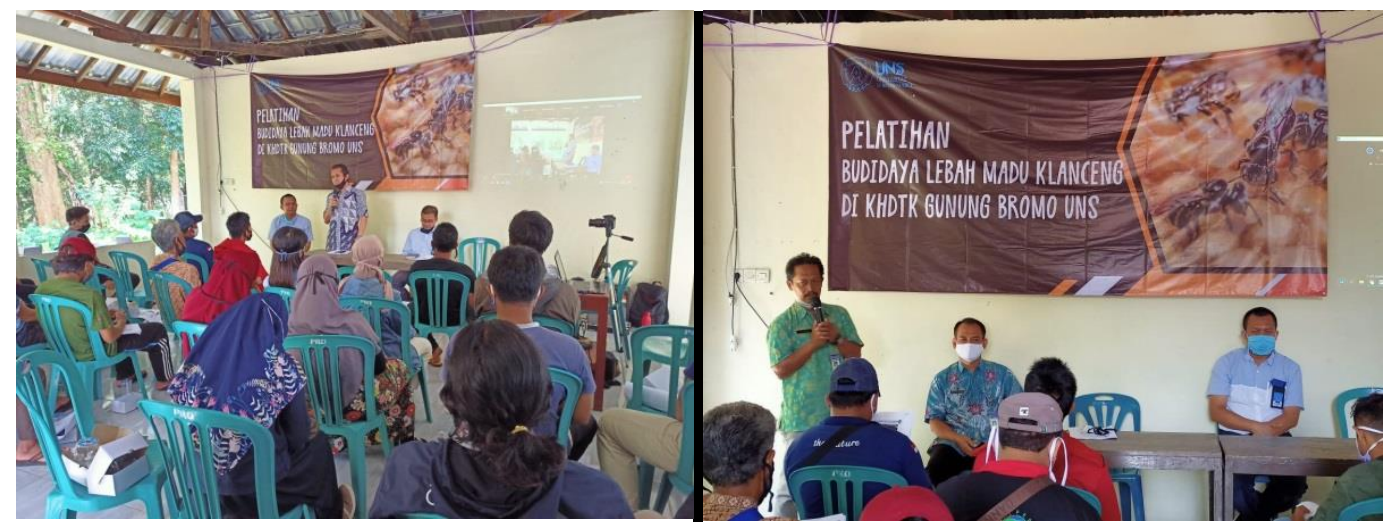

Gambar 1. Kegiatan pelatihan kelas budidaya lebah klanceng

Lebah madu yang telah dibudidayakan di Indonesia dan memiliki prospek tinggi sebagai sumber ekonomi alternatif salah satunya adalah lebah madu klanceng.Lebah klanceng ini merupakan salah satu jenis lebah tanpa sengat yang mampu menghasilkan madu dan propolis dalam jumlah tertentu dan memiliki khasiat yang baik bagi tubuh diantaranya menghambat pertumbuhan bakteri di dalam tubuh (Nadhilla, 2014), potensi sebagai antikanker (Ahmed \& Othman, 2013), dan mempercepat penyembuhan luka (Al-Waili et al., 2011). Di Indonesia setidaknya terdapat 30 jenis lebah klanceng diantaranya yaitu Trigona laeviceps, $T$. incisa, $T$. itama, $T$. cincta, $T$. borneensis, $T$. thoracica, $T$. aliceae, $T$. fimbriata, $T$. javanica, $T$. nitidiventris, T. trochanterica, T. ventralis, $T$. canifrons, dan T. genalis (Rasmussen, 2008). Adapun jenis lebah klanceng yang dibudidayakan oleh KHDTDK Gunung Bromo saat ini adalah jenis Trigona laeviceps dan Tetragonula sp. Di dalam melakukan pemeliharaan lebah klanceng hal utama yang harus diperhatikan adalah ketersediaan pakan (Erwan et al., 2020). Pakan lebah klanceng berasal dari berbagai macam jenis tumbuhan yang menghasilkan nektar dan polen. Beberapa jenis tumbuhan sumber pakan bagi lebah klanceng yaitu Carica papaya, Nephelium longan, Acacia auriculiformis, Eucalyptus nandiniana, Amaranthus spinnosus, Cosmos caudatus, Clitoria ternatea, Zea mays, Averrhoa carambola, Talinum paniculatum, Capsicum annuum, Coleus scutellarioides, dan Impatiens balsamina (Nugroho \& Soesilohadi, 2014). Di KHDTK saat ini sudah mulai menanam beranekaragam jenis tanaman penghasil nektar di antaranya yaitu bunga matahari, bunga air mata pengantin, dan sumber pakan lainnya dari tegakan pinus.

\section{Pelatihan Praktik}

Setelah melaksanakan sosialisasi dan pelatihan kelas, kegiatan berikutnya berupa pelatihan praktik di lapangan. Selama proses kegiatan berlangsung (Gambar 2), peserta menunjukkan antusias yang tinggi karena kegiatan budidaya lebah klanceng merupakan sebuah hal yang baru di kawasan KHDTK Gunung Bromo. Kegiatan pelatihan praktik meliputi penjelasan awal terkait jenis-jenis lebah klanceng, teknik memecah koloni menjadi beberapa kotak sarang, ketersediaan pakan yang diperlukan oleh lebah klanceng agar dapat menghasilkan madu yang optimal, teknik pemanenan madu, dan pengolahan akhir madu yang diperoleh berupa pemisahan kotoran dan madu murni. Setelah dilakukannya pelatihan praktik, peserta mendapatkan gambaran mengenai teknik budidaya secara keseluruhan dan ke depannya masyarakat dapat mempraktikkan secara langsung budidaya lebah klanceng di pekarangan rumah masing-masing. 


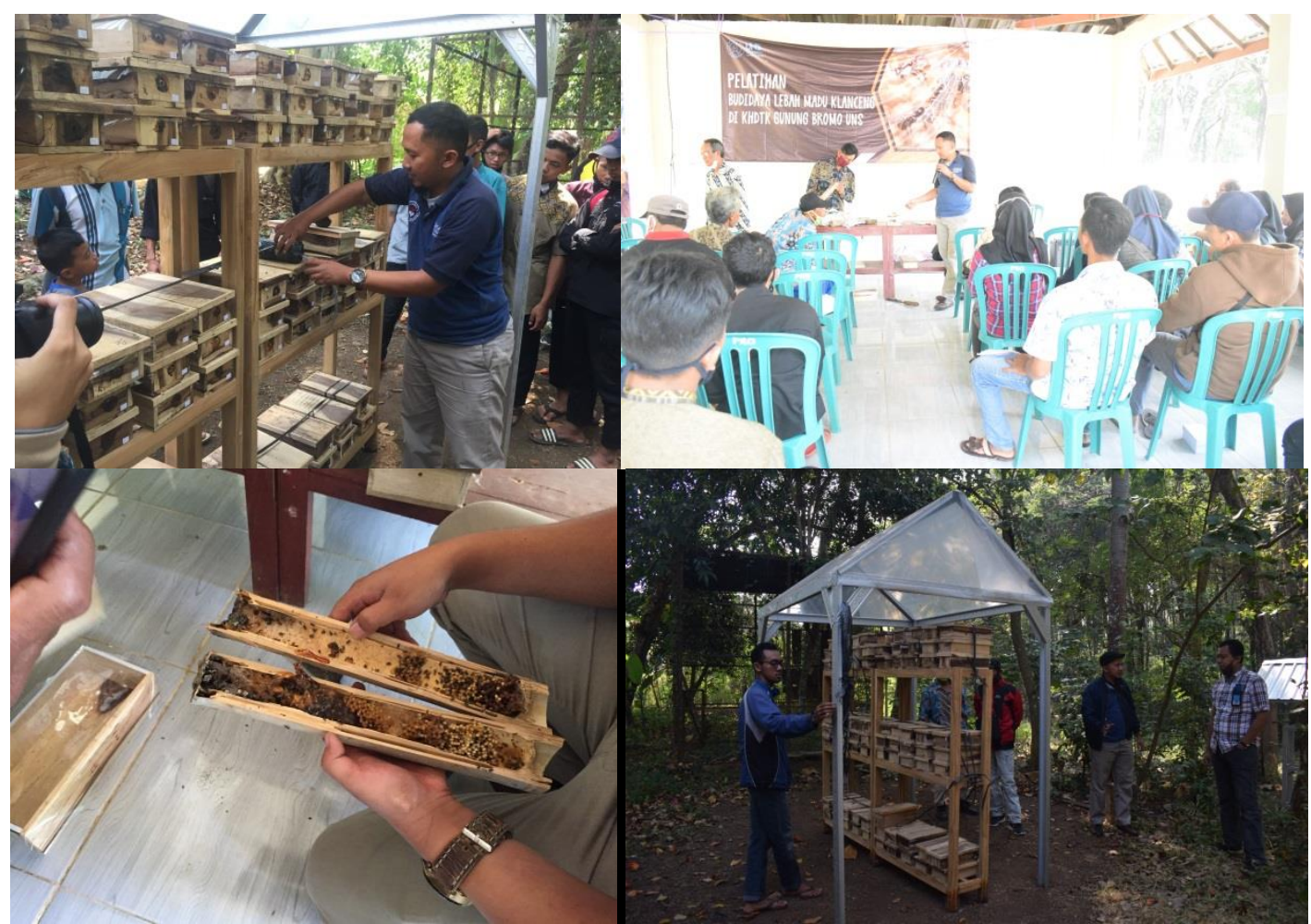

Gambar 2. Kegiatan praktik budidaya lebah klanceng

\section{Pemanenan}

Sebelum masyarakat melakukan praktik pemanenan secara langsung, tim pengabdian memberikan contoh dalam pemanenan madu klanceng. Proses pemanenan madu klanceng menggunakan beberapa alat sederhana yaitu alat peniris dan pisau sayat. Proses pemanenan harus diperhatikan secara seksama agar lebah ratu tidak ikut terangkat, beberapa bagian dari sarang yang masih berisi madu dan bee bread sebaiknya diletakkan kembali ke kotak lebah sebagai cadangan makanan bagi ratu lebah. Dalam proses pemanenan, terdapat beberapa produk yang bisa dihasilkan yaitu madu, bee pollen, dan propolis, khusus bee pollen dan propolis harus dilakukan proses ekstraksi lebih lanjut. Madu yang sudah disaring kemudian disimpan ke dalam wadah tertutup untuk selanjutnya dikemas ke dalam botol.

\section{Pendampingan dan Pengelolaan Produk}

Setelah mengikuti pelatihan kelas dan praktik, para peserta dari Karang Taruna Tunas Harapan dan Karang Taruna Bakti Manunggal diarahkan untuk membentuk kelompok pengembang usaha lebah klanceng. Prinsipnya adalah dibentuknya sistem kerjasama antara pihak pengelola KHDTK Gunung Bromo dengan masyarakat. Kerjasama tersebut berupa kesepakatan bahwa kotak lebah tetap berada di kawasan KHDTK, akan tetapi dalam pengelolaannya akan dilaksanakan oleh masyarakat. Hal ini dilakukan agar pada tahap awal pengembangan budidaya lebah klanceng dapat berjalan lancar dan optimal. Selain itu, di dalam kawasan hutan sudah tersedia pakannya sehingga akan memudahkan masyarakat dalam melakukan pemantauan perkembangan koloni lebah klanceng.

Produk yang nantinya dihasilkan setelah beberapa bulan ke depan akan diarahkanagar dapat memiliki kualitas dan memenuhi standar pemasaran produk. Hal-hal yang diperhatikan meliputi standar kualitas produk (pengukuran kadar air), pengemasan (label dan botol), dan pemasaran produk (Hilmanto, 2010).

\section{Monitoring dan Evaluasi}

Kegiatan pelatihan budidaya lebah klanceng telah diikuti oleh 41 orang peserta, yang berasal dari Kelurahan Delingan dan Gedong. Dari seluruh peserta yang hadir, 15 orang mendaftarkan diri sebagai Kelompok Petani Lebah yang ke depannya akan berperan aktif dalam mengembangkan lebah klanceng. Kegiatan budidaya dipantau melalui komunikasi dengan Ketua Kelompok Petani Lebah meliputi kondisi peternakan, sumber pakan lebah, dan keaktifan anggota. Berdasarkan hasil monitoring sejauh ini kondisi peternakan masih kondusif 
dan koloni lebah terpelihara dengan baik Akan tetapi masih terkendala pada keanekaragaman sumber pakan sehingga dirasa perlu membuat kebun bunga sebagai sumber pakan lebah. Berkaitan dengan keaktifan anggota sejauh ini, sebagian besar anggota telah terlibat aktif dalam kegiatan budidaya. Sebagai bentuk tindak lanjut, tersedia klinik konsultasi budidaya lebah klanceng di KHDTK Gunung Bromo yang sewaktu-waktu dapat diakses oleh masyarakat. Kegiatan pengembangan lebah klanceng ini merupakan kegiatan tahap awal dalam rencana pengelolaan KHDTK Gunung Bromo UNS yang diharapkan dapat menjadi salah satu upaya untuk menciptakan sumber ekonomi alternatif bagi masyarakat sekitar hutan. Ke depannya masyarakat yang telah terlibat aktif dapat menjadi motor penggerak bagi masyarakat lainnya dalam berkreasi dan berinovasi. Tentu saja kegiatan pelatihan ini tidak hanya sebatas berbagi ilmu, akan tetapi juga akan diteruskan hingga pembentukan badan usaha, pengembangan produk, dan pemasarannya.

\section{KESIMPULAN}

Budidaya lebah madu klanceng merupakan salah satu bidang usaha yang memiliki prospek tinggi, terutama untuk dikembangkan di kawasan sekitar hutan. Pelibatan masyarakat sekitar hutan diharapkan dapat menjadi sumber ekonomi alternatif. Kegiatan pelatihan budidaya lebah madu klanceng diikuti oleh Karang Taruna Tunas Harapan dan Karang Taruna Bakti Manunggal yang meliputi sosialisasi, pelatihan kelas, serta pelatihan praktik budidaya dan pemanenan. Peserta yang hadir memiliki antusias yang tinggi dalam pengembangan lebah klanceng. Kegiatan ini akan terus dilaksanakan hingga dapat membentuk sebuah unit usaha mandiri, yang saat ini telah terbentuk Kelompok Tani Lebah. Hal ini akan memberikan efek positif bagi pihak pengelola KHDTK Gunung Bromo karena masyarakat secara tidak langsung akan berperan dalam menjaga kelestarian hutan. Bagi masyarakat, selain mendapatkan keterampilan baru juga mendapatkan peluang untuk mengembangkan usaha sehingga tercipta perekonomian mandiri. Meskipun saat ini belum menunjukkan adanya peningkatan pendapatan yang disebabkan oleh kegiatan yang baru saja disosialisasikan kepada masyarakat, akan tetapi tidak menutup kemungkinan usaha budidaya lebah klanceng sebagai sumber ekonomi alternatif bagi masyarakat di sekitar KHDTK Gunung Bromo akan berkembang.

\section{UCAPAN TERIMA KASIH}

Terima kasih disampaikan kepada UPT Pusat Pendidikan dan Pelatihan Kehutanan UNS yang telah membantu dan mendukung selama kegiatan di lokasi kegiatan serta kepada LPPM UNS yang memberikan dukungan dana kegiatan melalui Hibah Program Kemitraan Masyarakat (PKM) PNBP UNS tahun anggaran 2020.

\section{DAFTAR PUSTAKA}

Ahmad, M. (2020). Analisis pendapatan masyarakat dari budidaya lebah madu trigona (Trigona Sp) Desa Timusu Kecamatan Liliriaja Kabupaten Soppeng. In Universitas Muhammdiyah Makasar.

Ahmed, S., \& Othman, N. H. (2013). Honey as a potential natural anticancer agent: A review of its mechanisms. Evidence-Based Complementary and Alternative Medicine, 2013. https://doi.org/10.1155/2013/829070

Al-Waili, N. S., Salom, K., \& Al-Ghamdi, A. A. (2011). Honey for wound healing, ulcers, and burns; data supporting its use in clinical practice. The Scientific World Journal, 11(June 2015), 766-787. https://doi.org/10.1100/tsw.2011.78

Elpawati, Hudaya, U. M. D. A., \& Habibie, F. M. (2019). Paddy rice farming diversification with Trigona sp. in Pandeglang regency, Banten province (Case study: diversification income analysis of paddy rice business with bee cultivation). IOP Conference Series: Earth and Environmental Science, 383(1). https://doi.org/10.1088/1755-

1315/383/1/012019

Erwan, E., Purnamasari, D. K., \& Agustin, W. (2020). Pengaruh desain kotak terhadap produktivitas lebah Trigona sp. Jurnal Sains Teknologi \& Lingkungan, 6(2), 192. https://doi.org/10.29303/jstl.v6i2.206

Hilmanto, R. (2010). Produksi madu organik untuk pasar global dan industri. Jurnal Ilmu Pertanian Indone, 15(2), 88-95.

Kerisna, V., Diba, F., \& Wulandari, R. S. (2019). Identifikasi jenis lebah trigona spp. pada zona pemanfaatan hutan Desa Menua Sadap Kecamatan Embaloh Hulu Kabupaten Kapuas Hulu. Jurnal Tengkawang, 9(2), 82-91. 
KLHK. (2018a). Data dan informasi pemetaan tematik kehutanan Indonesia.

KLHK. (2018b). Status hutan dan kehutanan Indonesia 2018. In Kementerian Lingkungan Hidup dan Kehutanan RI.

Nadhilla, N. F. (2014). The activity of antibacterial agent of honey against Staphylococcus aureus. J Majority, 3(7), 94-101.

Nugroho, R. B., \& Soesilohadi, R. H. (2014). Identifikasi macam sumber pakan lebah trigona sp (Hymenoptera: Apidae) di Kabupaten Gunungkidul. Biomedika, 7(2), 42-45.

Pribadi, A. (2020). Produktivitas panen propolis mentah lebah Trigona itama cockerell (Hymenoptera: Apidae) menggunakan propolis trap dan manipulasi lingkungan di Riau. A Scientific Journal, 37(2), 60-68. https://doi.org/10.20884/1.mib.2020.37.2. 1045
Rasmussen, C. (2008). Catalog of the IndoMalayan/Australasian stingless bees (Hymenoptera: Apidae: Meliponini). Zootaxa, 1935(1), 1-80. https://doi.org/10.11646/zootaxa.1935.1.1 Sunderlin, W. D., \& Resosudarmo, I. A. (1997). Laju dan penyebab deforestasi di Indonesia: penelaahan kerancuan dan penyelesaiannya. Laju Dan Penyebab Deforestasi Di Indonesia: Penelaahan Kerancuan Dan Penyelesaiannya, 9(1), 125. https://doi.org/10.17528/cifor/000057

Syaifudin, S. M. (2020). Budidaya pakan lebah Trigona sp. dengan apiculture agroforestry system di Kelurahan Anjungan Melancar, Kecamatan Anjungan Kabupaten Mempawah. Jurnal Ilmiah Pangabdhi, 6(1), 17-24. https://doi.org/10.21107/pangabdhi.v6i1.6 932 